\title{
Monitoring prevention or emergence of HIV drug resistance: results of a population-based foundational survey of early warning indicators in mainland Tanzania
}

James M Juma ${ }^{1 *}$, Jenny K Tiberio ${ }^{2}$, Mathias I Abuya ${ }^{1,4}$, Bonita K Kilama ${ }^{1}$, Geoffrey R Somi ${ }^{1}$, Veryeh Sambu ${ }^{1}$, Richard Banda ${ }^{3}$, Boniphace S Jullu ${ }^{5}$ and Angela A Ramadhani ${ }^{1}$

\begin{abstract}
Background: In Tanzania, routine individual-level testing for HIV drug resistance (HIVDR) using laboratory genotyping and phenotyping is not feasible due to resource constraints. To monitor the prevention or emergence of HIVDR at a population level, WHO developed generic strategies to be adapted by countries, which include a set of early warning indicators (EWIS).

Methods: To establish a baseline of EWIs, we conducted a retrospective longitudinal survey of 35 purposively sampled care and treatment clinics in 17 regions of mainland Tanzania. We extracted data relevant for four EWIs (ART prescribing practices, patients lost to follow-up 12 months after ART initiation, retention on first-line ART at 12 months, and ART clinic appointment keeping in the first 12 months) from the patient monitoring system on patients who initiated ART at each respective facility in 2010. We uploaded patient information into WHO HIVResNet excel-based tool to compute national and facility averages of the EWIs and tested for associations between various programmatic factors and EWI performance using Fisher's Exact Test.

Results: All sampled facilities met the WHO EWI target (100\%) for ART prescribing practices. However, the national averages for patients lost to follow-up 12 months after ART initiation, retention on first-line ART at 12 months, and ART clinic appointment keeping in the first 12 months fell short, at 26\%, 54\% and 38\%, respectively, compared to the WHO targets $\leq 20 \%, \geq 70 \%$, and $\geq 80 \%$. Clinics with fewer patients lost to follow-up 12 months after ART initiation and more patients retained on first-line-ART at 12 months were more likely to have their patients spend the longest time in the facility (including wait-time and time with providers), $(p=0.011$ and 0.007 , respectively).

Conclusion: Tanzania performed very well in EWI 1a, ART prescribing practices. However, its performance in other three EWIs was far below the WHO targets. This study provides a baseline for future monitoring of EWIs in Tanzania and highlights areas for improvement in the management of ART patients in order not only to prevent emergence of HIVDR due to programmatic factors, but also to improve the quality of life for ART patients.
\end{abstract}

Keywords: Tanzania, HIV and AIDS, Care and treatment, Antiretroviral therapy (ART), Prevention, Emergence, Monitoring, HIV drug resistance (HIVDR), Early warning indicators

\footnotetext{
* Correspondence: jj162us@yahoo.com

${ }^{1}$ Ministry of Health and Social Welfare, The National AIDS Control

Programme (NACP), P.O. Box 11857, Dar es Salaam, Tanzania

Full list of author information is available at the end of the article
} 


\section{Background}

Antiretroviral therapy (ART) extends the lives of persons living with HIV and AIDS and improves the quality of their lives [1,2]. The rapid increase in ART coverage in low- and middle-income countries, especially in Sub-Saharan Africa, has also led to a clear decline in premature mortality $[3,4]$. ART, however, is not without complications, and suboptimal adherence can lead to therapeutic failure and the development of antiretroviral resistance [2]. The development of resistance requires changes in ART regimens with limited therapeutic choices each time resistance occurs. Additionally, individuals with drug-resistant HIV strains can transmit them to infants or sexual and needle-sharing partners, leading to infections that are already resistant to first-line therapy and more difficult to treat [2].

In Tanzania, like most low-income country settings, routine individual-level testing for HIV drug resistance (HIVDR) using laboratory genotyping and phenotyping is not feasible due to resource constraints $[5,6]$. To monitor the appearance of HIVDR at the population level, the World Health Organization (WHO) developed a generic protocol for each country to adapt based on the routine patient monitoring system (PMS) in order to monitor and mitigate HIVDR [5]. The protocol focuses on eight elements: (i) creating an HIVDR technical working group to develop and implement the strategy, (ii) monitoring HIVDR early warning indicators (EWIs) at ART sites, (iii) conducting sentinel monitoring of HIVDR during treatment, (iv) conducting HIVDR threshold surveys to assess the incidence of transmitted HIVDR, (v) establishing an HIVDR database, (vi) designating an in-country or regional WHO-accredited HIVDR genotyping laboratory, (vii) conducting a national-level annual HIVDR situation review and making recommendations and (viii) the production of an annual report containing evidence-based recommendations to minimize the emergence and transmission of HIVDR. The EWIs, in particular, are attractive for ongoing monitoring because salient data can be retrieved from national ART PMSs [7], at relatively low cost and quicker than the laboratory based assays for the assessment of HIVDR mutations.

A limited number of studies are available from Africa that assesses EWI performance [6,8-11], and none from Tanzania. Furthermore, we could not find any studies that attempt to use programmatic factors as predictors for EWI success. Using four indicators that could be captured using the existing PMS, we undertook a baseline facility-level survey to a) ascertain Tanzanian national performance against WHO targets for four HIVDR EWIs and b) determine the correlates of achievements or failures in reaching the targets.

\section{Methods}

\section{Overall study design}

We conducted a retrospective longitudinal survey in 35 purposively sampled care and treatment clinics (CTCs) of patient cohorts who initiated ART in those facilities in 2010.

\section{Setting}

The Tanzanian health system is comprised of referral hospitals, regional hospitals, district hospitals, health centres and dispensaries. Dispensaries serve as the main point of care, larger health centres provide more complex treatment including inpatient care, and district and regional hospitals are equipped for surgery and referrallevel care. HIV and AIDS care and treatment services in Tanzania were approved by the government in October 2003 under the coordination of the National AIDS Control Programme (NACP), and ART roll-out began in October 2004. All facilities provide ART free of charge, and during the time of the study, there were 1,100 facilities nationwide providing ART. The target was to provide ART to 440,000 eligible patients by the end of 2010, but only 244,148 (55\%) patients had begun ART by July 2010. During the period of this evaluation, patients were eligible for first-line ART if they were HIV-infected, understood the implications of therapy, and fell into one of these three categories: patients in WHO clinical stage IV, patients in WHO clinical stage III with CD4 count less than $350 \mathrm{cells} / \mathrm{dl}$, or all patients with CD4 count less than 200 cells/dl regardless of clinical criteria [12]. All patients starting first-line ART in Tanzania are registered and followed-up clinically and using laboratory parameters. Normally ART patients attend clinics monthly for drug refills and continued medical check-up. A standardized national patient monitoring system, which is either paper-based or electronic, is in use at all facilities. The reports are produced quarterly through ART and pre-ART registers.

\section{Sampling}

All facilities providing HIV and AIDS care and treatment services were eligible for this survey. We constructed a national sample of facilities from 17 of the 21 regions in mainland Tanzania. We purposefully selected 35 CTCs to represent higher-level facilities (referral or regional hospitals) and lower-level facilities (district hospitals or health centres) from each region to ensure representation of different administrative levels. Our sample included all four referral hospitals, which are distributed across the country's mainland. In Dar es Salaam Region, we sampled three facilities to account for the density of ART patients. We excluded private facilities because they are few in number, unevenly distributed, and their reporting to the central system has not been well established.

Using the WHO sampling guidance [13], we calculated minimum/finite sample sizes for each EWI, based on number of eligible patients (patients initiated on ART) for each study indicator in 2010, the year prior to the survey. 
We chose a starting point from a list of charts based on our EWI sample start date (January 1, 2010) and then consecutively sampled charts until we reached minimum sample sizes required to achieve a 95\% confidence interval of $\pm 7 \%$ [13]. Health care providers (HCPs) from the sampled facilities conducted the data abstraction for HIVDR EWIs. This approach aimed to build local capacities of facility staffs to be able to assess the programmatic factors associated with HIVDR using their own data. HCPs only included the charts of adult patients (age $\geq 15$ years) who initiated ART at their respective facility. They excluded files belonging to patients who transferred in while on ART from another facility after January 2010 in order to avoid double counting had they also been sampled from the facility where they initiated ART. Patients who transferred out (TOs) of the study facilities were eligible for analysis of indicator 1a, regardless of transfer out dates. However, the TOs were excluded from analyses of indicators 2 and 3a only if the transfer out date was during the study period and of indicator $5 \mathrm{~b}$ if the transfer out date was before the first scheduled appointment after ART initiation.

\section{Measurement}

We gathered survey data using specially designated EWI data abstraction tools. However, our selection of these particular four indicators was based on routinely collected data from NACP's existing PMS. The four EWIs for which we abstracted data were:

EWI 1a: Percentage of [adult] patients initiating ART at the site during a selected time period who are initially prescribed, or who initially pick up from the pharmacy, an appropriate first-line ART regimen. We determined if patients were initiated on appropriate first-line regimen as per national guidelines and $\mathrm{WHO}$ recommendations $[12,14]$.

EWI 2: Percentage of patients initiating ART at the site in a selected time period who are lost to follow-up (LTFU) during the 12 months after starting ART. We defined LTFU as a patient's failure to attend the clinic for 90 consecutive days (three months) following their last visit, which is NACP's and WHO's standard definition.

EWI 3a: Percentage of adult patients initiating ART at the site during a selected time period who are taking an appropriate first-line ART regimen 12 months later. Being on first-line therapy included all mutual drug substitutions and combinations within this regimen category.

EWI 5b: Percentage of patients initiating ART at the site during a selected time period who attended all clinic appointments on time during the first 12 months of ART. In keeping with the WHO definition, we defined missing a clinic appointment as failing to appear on the same day or within seven days of the expected or scheduled clinic consultation date.

Two to three HCPs from each facility received training on nationally validated data abstraction techniques using facility-held care and treatment patient cards (CTC2). The National HIVDR Technical Working Group provided on-site mentorship and supportive supervision during data abstraction to ensure that the tools were filled correctly. Mentors and supervisors verified the data in completed tools. They also administered structured questionnaires to HCPs to collect information on programmatic factors such as facility maturity (number of months providing ART services), average hours clinics are open per day, average time patients spend in the clinic (defined as total time spent at the clinic, cumulatively in all departments, while waiting for and receiving services), and other characteristics in order to understand facility-level determinants of EWI performance.

\section{Analysis}

Based on WHO guidance and sampling methods described in these referenced documents $[10,12,14]$, we calculated that 3,608 charts would need to be abstracted to have enough power to achieve $\pm 7 \%$ precision, $95 \%$ of the time. We uploaded the abstracted patient information into WHO HIVResNet excel-based tool [13] to determine the facility-level weighted averages of EWI performance. We assessed national performance for each EWI by comparing the proportion of clinics that met WHO criteria for each indicator. The WHO's set targets are $100 \%$ for EWI $1 \mathrm{a}, \leq 20 \%$ for EWI $2, \geq 70 \%$ for EWI $3 \mathrm{a}$ and $\geq 80 \%$ for EWI $5 \mathrm{~b}$. We aggregated facility-level data and computed the proportion of facilities that met the WHO EWI targets by various facility characteristics. We analyzed the association between meeting WHO EWIs and facility characteristics using Fisher's Exact Test in Stata v. 11 (Stata Corporation, College Station, Texas, USA).

\section{Ethical considerations}

The HIVDR monitoring strategy in Tanzania, which includes EWIs, received ethical approval from Tanzania's National Institute for Medical Research's (NIMR) Independent Review Board in 2008 (Ref No NIMR/HQ/R.89/ Vol. IX.746). The analysis presented in this report is based on secondary analyses of unlinked data; no contact with human subjects occurred.

\section{Results}

We invited 35 facilities to participate in the survey, and all agreed. The 35 facilities included 28 public and 7 faith-based facilities; 4 referral hospitals, 17 non-referral 
hospitals and 14 health centers; and 20 urban, 6 semiurban and 9 rural facilities. During 2010, a total of 13,466 adult patients began ART at these facilities; we abstracted data from 3,608 (27\%) charts. All facilities adhered to the national ART management guidelines regarding eligibility for ART initiation. Six facilities had been providing ART services for longer than five years while 14 had been in operation for less than three years (Table 1).

Of the 3,608 charts we reviewed from sampled facilities, the weighted national average was $100 \%$ for EWI 1a, 26\% (95\% CI 25-26) for EWI 2, 54\% (95\% CI 53-54) for EWI 3a, and 38\% (95\% CI 37-38) for EWI 5b (Table 1). Of the 35 clinics, all met the WHO target for EWI 1a, 17 clinics (49\%) for EWI 2, 10 clinics (29\%) for EWI $3 a$ and 1 clinic (3\%) for EWI $5 b$ (Table 2). None of the clinics met all four EWI targets.

Twenty-nine (83\%) ART facilities were operating their clinics for at least eight hours per day. Patients at $6(17 \%)$ facilities travelled an average of less than 10 kilometers, whereas those at 16 (46\%) facilities travelled over 30 kilometers on average to attend the clinic. At 14 (40\%) facilities the average time patients spent in the clinic (which included wait time and time spent with providers) was less than 60 minutes, and at $6(17 \%)$ it was over 180 minutes. Thirty (86\%) facilities had no supplementary ART dispensing locations; only two (6\%) ART facilities provided both refill sites and outreach services for ART. Twenty-five (71\%) facilities provided home-based services.

Facilities that met EWI 2 and 3a were more likely to have their patients spend more than 180 minutes on average in the clinic ( $\mathrm{p}=0.011$ and 0.007 , respectively), Table 3 . The only facility that met EWI $5 \mathrm{~b}$ was a faithbased urban referral hospital operating for less than 8 hours per day open.

\section{Discussion}

We found that all surveyed facilities had $100 \%$ of patients initiated on appropriate first-line ART regimens

Table 1 Weighted averages of HIV drug resistance EWI performance from 35 HIV care and treatment facilities, aggregated by programmatic characteristics, Tanzania, 2010

\begin{tabular}{|c|c|c|c|c|c|c|}
\hline \multicolumn{3}{|c|}{ Programmatic characteristics } & \multicolumn{4}{|c|}{ HIVDR early warning indicators (EWIs) } \\
\hline & \multirow[b]{3}{*}{$\begin{array}{c}\text { Facility counts } \\
\text { n (\%) }\end{array}$} & \multirow[b]{3}{*}{$\begin{array}{l}\text { Total \# initiated } \\
\text { on ART in } 2010\end{array}$} & \multirow{3}{*}{$\begin{array}{c}\text { EWI 1a, ART } \\
\text { prescription } \\
\text { practices } \\
\text { WHO target: } \\
100 \% \\
\%\end{array}$} & \multirow{3}{*}{$\begin{array}{l}\text { EWI 2, patients } \\
\text { LTFU at } \\
12 \text { months } \\
\text { WHO target: } \\
\leq 20 \% \\
\%(95 \% \mathrm{Cl})\end{array}$} & \multirow{3}{*}{$\begin{array}{c}\text { EWI } 3 a \text {, retention } \\
\text { on } 1 \text { st line ART } \\
\text { at } 12 \text { months } \\
\text { WHO target: } \\
\geq 70 \% \\
\%(95 \% \mathrm{Cl})\end{array}$} & \multirow{3}{*}{$\begin{array}{c}\text { EWI } 5 \mathrm{~b} \text {, clinic } \\
\text { appointment keeping } \\
\text { in first } 12 \text { months } \\
\text { WHO target: } \\
\geq 80 \% \\
\%(95 \% \mathrm{Cl})\end{array}$} \\
\hline & & & & & & \\
\hline & & & & & & \\
\hline $\begin{array}{l}\text { National average } \\
\text { performance on EWIs }\end{array}$ & $35(100)$ & 13,466 & 100 & $26(25-26)$ & $54(53-54)$ & $38(37-38)$ \\
\hline \multicolumn{7}{|c|}{ Facility administrative level } \\
\hline Referral hospitals & $4(11)$ & 2346 & 100 & $25(24-26)$ & $53(52-55)$ & $54(53-55)$ \\
\hline Non-referral hospitals & $17(49)$ & 8512 & 100 & $22(21-23)$ & $56(55-56)$ & $37(36-37)$ \\
\hline Health centers & $14(40)$ & 2608 & 100 & $32(30-33)$ & $51(49-52)$ & $31(30-32)$ \\
\hline \multicolumn{7}{|c|}{ Facility geographical locality } \\
\hline Urban & $20(57)$ & 11,604 & 100 & $22(22-23)$ & $56(55-56)$ & $40(40-41)$ \\
\hline Semi-urban & $6(17)$ & 601 & 100 & $43(41-46)$ & $39(37-41)$ & $29(28-30)$ \\
\hline Rural & $9(26)$ & 1261 & 100 & $27(26-28)$ & $55(54-56)$ & $33(32-34)$ \\
\hline \multicolumn{7}{|l|}{ Facility ownership } \\
\hline Public & $28(80)$ & 9661 & 100 & $24(23-25)$ & $54(53-55)$ & $34(33-34)$ \\
\hline Faith-based & $7(20)$ & 3805 & 100 & $30(29-31)$ & $53(52-54)$ & $50(49-51)$ \\
\hline \multicolumn{7}{|c|}{ Facility maturity (years providing ART services) } \\
\hline$>5$ & $6(17)$ & 4684 & 100 & $18(17-19)$ & $61(60-62)$ & $47(46-48)$ \\
\hline $3-5$ & $15(43)$ & 6174 & 100 & $25(24-26)$ & $52(51-53)$ & $37(37-38)$ \\
\hline$<3$ & $14(40)$ & 2608 & 100 & $32(30-33)$ & $51(49-52)$ & $31(30-32)$ \\
\hline Median: 4 years IQR: $2-5$ & & & & & & \\
\hline
\end{tabular}

IQR interquartile range.

EWI 1a, \% of adult patients initiating ART at the site who are initially prescribed, or who initially pick up from the pharmacy, an appropriate first-line ART regimen. EWI 2,\% of patients initiating ART at the site who are lost to follow-up (LTFU) 12 months after ART initiation.

EWI 3a, \% of adult patients initiating ART at the site who are taking an appropriate first-line ART regimen 12 months later.

EWI $5 b, \%$ of patients initiating ART at the site who attended all scheduled or expected clinical consultations on time during the first 12 months. 
Table 2 Proportion of ART facilities that meet WHO EWI targets, aggregated by programmatic characteristics, Tanzania, 2010

\begin{tabular}{|c|c|c|c|c|c|}
\hline \multicolumn{2}{|l|}{ Programatic characteristics } & \multicolumn{4}{|c|}{ HIVDR early warning indicators (EWIs) } \\
\hline & & $\begin{array}{c}\text { EWI 1a, ART } \\
\text { prescribing practices }\end{array}$ & $\begin{array}{l}\text { EWI 2, patients LTFU } \\
\text { at } 12 \text { months }\end{array}$ & $\begin{array}{l}\text { EWI } 3 a \text {, retention on } 1 \mathrm{st} \\
\text { line ART at } 12 \text { months }\end{array}$ & $\begin{array}{l}\text { EWI } 5 b \text {, clinic appointment } \\
\text { keeping in first } 12 \text { months }\end{array}$ \\
\hline & & WHO target: $100 \%$ & WHO target: $\leq 20 \%$ & WHO target: $\geq 70 \%$ & WHO target: $\geq 80 \%$ \\
\hline & Frequency & n (\%) & n (\%) & n (\%) & n (\%) \\
\hline $\begin{array}{l}\text { National average } \\
\text { performance on EWls }\end{array}$ & $(\mathrm{N}=35)$ & $35(100)$ & $17(49)$ & $10(29)$ & $1(3)$ \\
\hline \multicolumn{6}{|l|}{ Facility administrative level } \\
\hline Referral hospitals & 4 & $4(100)$ & $2(50)$ & $0(0)$ & $1(25)$ \\
\hline Non-referral hospitals & 17 & $17(100)$ & $7(41)$ & $5(29)$ & $0(0)$ \\
\hline \multirow[t]{2}{*}{ Health centers } & 14 & $14(100)$ & $8(57)$ & $5(36)$ & $0(0)$ \\
\hline & & & $p=0.793$ & $p=0.512$ & $p=0.114$ \\
\hline \multicolumn{6}{|l|}{ Facility locality } \\
\hline Urban & 20 & $20(100)$ & $11(55)$ & $5(25)$ & $1(5)$ \\
\hline Semi-urban & 6 & $6(100)$ & $2(33)$ & $1(17)$ & $0(0)$ \\
\hline \multirow[t]{2}{*}{ Rural } & 9 & $9(100)$ & $4(44)$ & $4(44)$ & $0(0)$ \\
\hline & & & $p=0.727$ & $p=0.582$ & $p=1.000$ \\
\hline \multicolumn{6}{|l|}{ Facility ownership type } \\
\hline Public & 28 & $28(100)$ & $13(46)$ & $8(29)$ & $0(0)$ \\
\hline \multirow[t]{2}{*}{ Faith-based } & 7 & $7(100)$ & $4(57)$ & $2(29)$ & $1(14)$ \\
\hline & & & $p=0.691$ & $p=1.000$ & $p=0.200$ \\
\hline \multicolumn{6}{|c|}{ Facility maturity (years providing ART services) } \\
\hline$>5$ & 6 & $6(100)$ & $4(67)$ & $2(33)$ & $1(17)$ \\
\hline $3-5$ & 15 & $15(100)$ & $5(33)$ & $3(20)$ & $0(0)$ \\
\hline \multirow[t]{2}{*}{$<3$} & 14 & $14(100)$ & $8(57)$ & $5(36)$ & $0(0)$ \\
\hline & & & $p=0.324$ & $p=0.611$ & $p=0.171$ \\
\hline
\end{tabular}

EWI 1a, \% of adult patients initiating ART at the site who are initially prescribed, or who initially pick up from the pharmacy, an appropriate first-line ART regimen. EWI 2,\% of patients initiating ART at the site who are lost to follow-up (LTFU) 12 months after ART initiation.

EWI $3 a, \%$ of adult patients initiating ART at the site who are taking an appropriate first-line ART regimen 12 months later.

EWI $5 b, \%$ of patients initiating ART at the site who attended all scheduled or expected clinical consultations on time during the first 12 months.

(EWI 1a). Meeting EWI 1a is a critical success because initiating patients on a mixture of therapies would a) complicate initiation protocols and require routine genotyping at baseline, which is not currently viable in Tanzania; b) tap into usable therapies that should be conserved for patients who fail first-line treatment; c) preclude the system from monitoring patients who fail first-line and must be switched to second-line regimens, a crucial indicator for detecting resistance.

On the other hand, we found that none of the facilities surveyed met all four WHO EWI targets, and only one facility met EWI 5b (ART clinic appointment keeping during the first 12 months of ART). These results are very concerning, as missing even a few doses - particularly during the first six months of therapy when viral loads are high - can lead to treatment failure and drug resistance $[2,15,16]$. A WHO report found that among 27 African countries surveyed, less than half of the clinics met this target, and globally, less than three fifths of the clinics met EWI 5b [5].

Anecdotally, pharmacy record keeping in Tanzania is inconsistent, therefore missing appointments is the next best proxy for estimating treatment interruption [5]. It is possible, however, that some patients are missing ART clinic appointments but still picking up their antiretrovirals at the pharmacy, so we cannot conclusively say that treatment interruption is occurring at this magnitude. Nevertheless, the results for EWI 5b are alarming. Furthermore, WHO's recently harmonized set of early warning indicators no longer includes EWI 5 [17], which means appointment keeping will no longer be a proxy for ART adherence and possible drug failure.

We also found that facilities whose patients spent the most time in the clinic (more than 3 hours, cumulatively in all departments including wait time), were more likely 
Table 3 Proportion of ART facilities that met WHO EWI targets, aggregated by additional programmatic/ facility characteristics, Tanzania, 2010

\begin{tabular}{|c|c|c|c|c|c|}
\hline & Frequency & $\begin{array}{c}\text { EWI 1a, ART } \\
\text { prescribing practices } \\
\text { WHO target: } 100 \% \\
n(\%)\end{array}$ & $\begin{array}{c}\text { EWI 2, patients } \\
\text { LTFU at } 12 \text { months } \\
\text { WHO target: } \leq 20 \% \\
n(\%)\end{array}$ & $\begin{array}{c}\text { EWI 3a, retention on } 1 \text { st } \\
\text { line ART at } 12 \text { months } \\
\text { WHO target: } \geq 70 \% \\
n(\%)\end{array}$ & $\begin{array}{c}\text { EWI } 5 \mathrm{~b} \text {, Clinic appointment } \\
\text { keeping in first } 12 \text { months } \\
\text { WHO target: } \geq 80 \% \\
n(\%)\end{array}$ \\
\hline \multicolumn{6}{|l|}{ Average opening time (hours) } \\
\hline Clinic \& pharmacy: $\geq 8$ hrs & 29 & $29(100)$ & $16(55)$ & $10(35)$ & $0(0)$ \\
\hline \multirow[t]{2}{*}{ Clinic \& pharmacy: $<8$ hrs } & 6 & $6(100)$ & $1(17)$ & $0(0)$ & $1(17)$ \\
\hline & & & $p=0.177$ & $p=0.640$ & $p=0.171$ \\
\hline \multicolumn{6}{|c|}{ Average distance (kilometers, $\mathrm{km}$ ) travelled by patient } \\
\hline$\geq 51 \mathrm{~km}$ & 10 & $10(100)$ & $5(50)$ & $3(30)$ & $1(10)$ \\
\hline $21-50 \mathrm{~km}$ & 10 & $10(100)$ & $5(50)$ & $3(30)$ & $0(0)$ \\
\hline $11-20 \mathrm{~km}$ & 8 & $8(100)$ & $6(75)$ & $3(38)$ & $0(0)$ \\
\hline \multirow[t]{2}{*}{$\leq 10 \mathrm{~km}$} & 7 & $7(100)$ & $1(14)$ & $1(14)$ & $0(0)$ \\
\hline & & & $p=0.162$ & $p=0.885$ & $p=1.000$ \\
\hline \multicolumn{6}{|c|}{ Average time (minutes) patient spent at the Clinic } \\
\hline$>180$ minutes & 6 & $6(100)$ & $6(100)$ & $5(83)$ & $0(0)$ \\
\hline $60-180$ minutes & 15 & $15(100)$ & $7(47)$ & $3(20)$ & $1(7)$ \\
\hline \multirow[t]{2}{*}{$<60$ minutes } & 14 & $14(100)$ & $4(29)$ & $2(14)$ & $0(0)$ \\
\hline & & & $p=0.011^{*}$ & $p=0.007^{*}$ & $p=1.000$ \\
\hline \multicolumn{6}{|c|}{ Supplementary ART dispensing locations } \\
\hline Refill, outreach or both & 5 & $5(100)$ & $2(40)$ & $2(40)$ & $0(0)$ \\
\hline \multirow[t]{2}{*}{ Neither } & 30 & $30(100)$ & $15(50)$ & $8(27)$ & $1(3)$ \\
\hline & & & $p=1.000$ & $p=0.610$ & $p=1.000$ \\
\hline \multicolumn{6}{|l|}{ Home based services } \\
\hline Yes & 25 & $25(100)$ & $13(52)$ & $6(24)$ & $1(4)$ \\
\hline \multirow[t]{2}{*}{ No } & 10 & $10(100)$ & $4(40)$ & $4(40)$ & $0(0)$ \\
\hline & & & $p=0.711$ & $p=0.421$ & $p=1.000$ \\
\hline
\end{tabular}

*Statistically significant.

EWI 1a, \% of adult patients initiating ART at the site* who are initially prescribed, or who initially pick up from the pharmacy, an appropriate first-line ART regimen. EWI 2,\% of patients initiating ART at the site* who are lost to follow-up (LTFU) 12 months after ART initiation.

EWI $3 a, \%$ of adult patients initiating ART at the site* who are taking an appropriate first-line ART regimen 12 months later.

EWI $5 b, \%$ of patients initiating ART at the site* who attended all scheduled or expected clinical consultations on time during the first 12 months.

(without controlling for clinics' ART cohorts sizes) to fulfill EWI 2 (LTFU 12 months after ART initiation) and EWI 3a (retention on first-line ART at 12 months) than others. Since we are not able to distinguish wait time from time spent with providers, we have two possible explanations. If longer time spent in the clinic is, in fact, due to more patient-provider contact time, there is a sizeable body of literature on patient satisfaction relative to time spent with provider $[18,19]$, and we speculate that greater patient satisfaction may lead to lower rates of LTFU. We also theorize that patients who spend more time with their providers may understand and adhere to their regimen better, leading to improved retention on first-line regimens. Conversely, if longer visits were due to greater wait times, research shows that patient satisfaction may be high even when wait times are long $[20,21]$.
Furthermore, it is plausible that the association between longer wait times and higher EWI performance is confounded by higher quality services at some facilities.

Hypothetically, patients may be willing to wait longer at facilities they consider higher quality (with more skilled providers and better diagnostic equipment), while these facilities are also more likely to perform higher in EWIs. Nonetheless, the association between time spent in the clinic and performance in EWI 2 and 3a should be interpreted with caution, as measurement error and respondent bias may be a factor. If providers overestimated the average time they spend with patients, we would expect to see a smaller effect size after taking this into account.

We were not successful in identifying many significant predictors of high EWI performance. Referral hospitals 
did not perform better than lower level facilities with regard to patient retention on first-line ART (EWI 3a) as we expected. Perhaps this is because more experienced clinicians in referral hospitals may be better equipped to recognize patients who are failing their first-line regimen and move them to second-line therapy. We also expected that facilities with supplemental ART dispensing locations (such as refill sites and outreach services) and home based care would be more successful with LTFU and appointment keeping, but this was not the case. It is possible that with a few sampled facilities and only some facilities providing outreach services, that we did not have sufficient power to detect this difference. Lastly, we anticipated facilities whose patients walk longer average distances would perform worse overall, but perhaps some patients choose to travel to more distal facilities to avoid the stigma of receiving treatment near their homes.

Our study is subject to several limitations. It is the first assessment of its kind undertaken in Tanzania, and in future studies, we hope to obtain better measures for treatment interruption, as well as more robust measures of facility characteristics, such as patient visit times, to better understand how patients spending more time in the clinic results in less attrition and greater retention on first-line ART. Given the human resource shortages Tanzania faces, we are not suggesting that providers should spend more time with patients, but that understanding the factors that contribute to more efficient clinic visits is crucial for balancing human resource constraints with providing both effective and quality care. Secondly, our sample was not perfectly representative of all ART facilities in the nation, and we plan to extend subsequent surveys to areas not covered in this initial survey, including the private facilities, as well as to randomly sample lower-level facilities to avoid selection bias. Finally, there are inherent limitations in the survey methods we employed. We were unable to develop data on the WHO HIVDR EWIs that cannot be obtained from routine patient monitoring, which we plan to address with additional special surveys in our next monitoring round. Additionally, we plan in the future to triangulate EWI data, like those collected in this study, with HIVDR threshold and monitoring surveys, both of which are undergoing development. Despite these limitations, we believe that our data point out successes (initiating ART) and where our system needs immediate improvements (attrition, retention on first-line $\mathrm{ART}$ and clinic appointment keeping). It is with periodic surveys such as this that ART services in Tanzania can be improved to provide the best care and treatment for our patients.

\section{Conclusion}

In conclusion, Tanzania performed very well in EWI 1a, ART prescribing practices, but its performance in the other three EWIs fell far short of the WHO targets. This study provides a baseline for future monitoring of EWIs in Tanzania. It also conveys lessons learned for surveys that aim to identify practices contributing to the emergence or prevention of HIVDR. EWIs are a quicker assessment technique and they are crucial for tracking HIVDR in resource-limited settings where individuallevel monitoring is not feasible. In addition to the national monitoring of EWIs, clinics should be empowered to use their own data to track EWIs more routinely at a facility level in order to address problems or gaps in a timely manner. With better understanding of the programmatic factors that contribute to decreased HIV drug resistance, we may continue to improve the quality of ART services provided for Tanzanians living with HIV and AIDS, and ultimately, the quality of their lives.

\section{Abbreviations}

AIDS: Acquired immunodeficiency syndrome; ART: Antiretroviral therapy; CTCs: Care and treatment clinics; EWl: Early warning indicator; HIV: Human immunodeficiency virus; HIVDR: HIV drug resistance HCPs - health care providers; LTFU: Lost to follow up; NACP: National AIDS control programme; NIMR: National institute for medical research; PMS: Patient monitoring system; WHO: World Health Organization.

\section{Competing interests}

The authors declare that they have no competing interests.

\section{Authors' contributions}

JMJ Tools design, survey field work, preliminary data aggregation and local feedback report compilation, secondary data analysis and primary and final manuscript write-up and approval. TJ, AM secondary data analysis and interpretation, and primary and final manuscript write up and approval. SGR, RAA, SV, BR, KB, JSB Tools design, Survey field work, preliminary data aggregation and Local feedback report compilation, final manuscript write-up and approval.

\section{Acknowledgments}

We convey our sincere gratitude to the Regional AIDS Control Coordinators of 17 regions for making data collection possible. We also recognize the special contributions from Mr. Bernard Rabiel, Mr. Joseph Nondi, Dr. Awene Gavyole, Ms. Neema Makyao and Dr. David Sando for their invaluable assistance in both tool design and field work for this survey. We would also like to express our great appreciation to Professor George Rutherford, Dr. Gilly Arthur, Dr. Mary Kibona and Ms. Suzanne Welty for their support and guidance in the manuscript development process. Finally, we are indebted to all the health care providers from the $35 \mathrm{HIV}$ care and treatment facilities that contributed data for this evaluation.

\section{Author details}

${ }^{1}$ Ministry of Health and Social Welfare, The National AIDS Control Programme (NACP), P.O. Box 11857, Dar es Salaam, Tanzania. ${ }^{2}$ University of California, San Francisco, Global Health Sciences, 50 Beale Street, Suite 1200, San Francisco, CA 94105-1823, USA. ${ }^{3}$ World Health Organization, Tanzania Country Office, P.O. Box 9292, Dar es Salaam, Tanzania. ${ }^{4}$ Afya Bora Consortium Global Health Leadership Fellowship Program (field attached fellow), University of Washington, 325 Ninth Avenue, Box 359909, Seattle, WA 98104-2499, USA. ${ }^{5}$ St. Francis University College of Health and Allied Sciences, P.O. Box 175, Ifakara, Morogoro, Tanzania.

Received: 25 June 2013 Accepted: 3 April 2014

Published: 11 April 2014 


\section{References}

1. Parsons TD, Braaten AJ, Hall CD, Robertson KR: Better quality of life with neuropsychological improvement on HAART. Health Qual Life Outcome 2006, 4:11. PubMed PMID: 16504114. Pubmed Central PMCID: 1397824.

2. Laing R, Hodgkin C: Overview of Antiretroviral Therapy, Adherence and Drug-Resistance. From Access to Adherence: the Challenges of Antiretroviral Treatment. Geneva: World Health Organization; 2006:21-31.

3. USAID: HIV/AIDS Health Profile: Sub-Saharan Africa. 2012. Available online at: http://pdf.usaid.gov/pdf_docs/pdacu659.pdf accessed April 102014.

4. Floyd S, Marston M, Baisley K, Wringe A, Herbst K, Chihana M, Kasamba I, Bärnighausen T, Urassa M, French N, Todd J, Zaba B: The effect of antiretroviral therapy provision on all-cause, AIDS and non-AIDS mortality at the population level-a comparative analysis of data from four settings in Southern and East Africa. Trop Med Int Health 2012, 17(8):e84-e93. PubMed PMID: 22943383. Pubmed Central PMCID: 3443384.

5. Bennett DE, Jordan MR, Bertagnolio S, Hong SY, Ravasi G, McMahon JH, Saadani A, Kelley KF: HIV drug resistance early warning indicators in cohorts of individuals starting antiretroviral therapy between 2004 and 2009: World Health Organization global report from 50 countries. Clin Infect Dis 2012, 54(Suppl 4):S280-S289. PubMed PMID: 22544188. Pubmed Central PMCID: 3338314

6. Hong SY, Jonas A, Dumeni E, Badi A, Pereko D, Blom A, Muthiani VS, Shiningavamwe AN, Mukamba J, Andemichael G, Barbara R, Bennett DE, Jordan MR: Population-based monitoring of HIV drug resistance in Namibia with early warning indicators. J Acquir Immune Defic Syndr 2010, 55(4):27-31. PubMed PMID: 20838224. Pubmed Central PMCID: 2974796.

7. The United Republic of Tanzania Ministry of Health and Social Welfare Tanzania Mainland: National Guidelines for the Management of HIV and AIDS Data Quality. 4th edition. Tanzania: National AIDS Control Programme (NACP); 2012. ISBN 978-9987-650-64-4.

8. Hedt BL, Wadonda-Kabondo N, Makombe S, Harries AD, Schouten EJ, Limbambala E, Hochgesang M, Aberle-Grosse J, Kamoto K: Early warning Indicators for HIV drug resistance in Malawi. Antivir Ther 2008, 13(Suppl 2):69-75.

9. Assessment of World Health Organization: HIV drug resistance early warning indicators: report of the Early Warning Indicator Advisory Panel meeting. Geneva: World Health Organization; 2011.

10. Sigaloff KC, Hamers RL, Menke J, Labib M, Siwale M, Ive P, Botes ME, Kityo C, Mandaliya K, Wellington M, Osibogun A, Geskus RB, Stevens WS, van Vugt M, Rinke de Wit TF: Early warning indicators for population-based monitoring of HIV drug resistance in 6 African countries. Clin Infect Dis 2012, 54(Suppl 4):S294-S299. PubMed PMID: 22544190.

11. Billong SC, Fokam J, Nkwescheu AS, Kembou E, Milenge P, Tsomo Z, Aghokeng AF, Mpoudi EN, Ndumbe PM, Colizzi V, Nfetam Elat JB: Early warning indicators for HIV drug resistance in Cameroon during the year 2010. Plos one 2012, 7(5):e36777.

12. The United Republic of Tanzania Ministry of Health and Social Welfare Tanzania Mainland: National Guidelines for the Management of HIV and AIDS, (Revised February 2009). 3rd edition. Tanzania: National AIDS Control Program; 2012.

13. World Health Organization: HIV Drug Resistance Early Warning Indicators: World Health Organization Indicators to Monitor HIV Drug Resistance Prevention at Antiretroviral Treatment Sites, June 2010 Update. Geneva: World Health Organization; 2010.

14. World Health Organization: Antiretroviral Therapy for HIV Infection in Adults and Adolescents: Recommendations for a Public Health Approach, 2006 Revision. Geneva: WHO; 2006.

15. Bennett DE, Myatt M, Bertagnolio S, Sutherland D, Gilks CF: Recommendations for surveillance of transmitted HIV drug resistance in countries scaling up antiretroviral treatment. Antivir Ther 2008, 13(Suppl 2):25-36. PubMed PMID: 18575189.

16. Bennett DE, Bertagnolio S, Sutherland D, Gilks CF: The World Health Organization's global strategy for prevention and assessment of HIV drug resistance. Antivir Ther 2008, 13(Suppl 2):1-13. PubMed PMID: 18578063.

17. World Health Organization Global Strategy for the Surveillance and Monitoring of HIV Drug Resistance: HIV Drug Resistance Report 2012. Geneva: World Health Organization; 2012.

18. Lin C-T, Albertson GA, Schilling LM, Cyran EM, Anderson SN, Ware L, Anderson RJ: Is patients' perception of time spent with the physician a determinant of ambulatory patient satisfaction? Arch Intern Med 2001, 161:1437-1442.
19. Wouters $E$, Heunis $C$, van Rensburg D, Meulemans H: Patient satisfaction with antiretroviral services at primary health-care facilities in the Free State, South Africa-a two-year study using four waves of cross-sectional data. BMC Health Serv Res 2008, 8:210. PubMed PMID: 18844998. Pubmed Central PMCID: 2575208.

20. Amanyire G, Wanyenze R, Alamo S, Kwarisiima D, Sunday P, Sebikaari G, Kamya M, Wabwire-Mangen F, Wagner G: Client and provider perspectives of the efficiency and quality of care in the context of rapid scale-up of antiretroviral therapy. AIDS Patient Care STDS 2010, 24(11):719-727.

21. Lo M, Welty S, Steinfeld R, Nampanda E, Kaaya S, Chalamilla G, Fawzi W, Hirschhorn L: Patient-reported health system responsiveness and experience with care at ARV clinics in Dar es Salaam, Tanzania. In 5th IAS Conference on HIV Pathogenesis and Treatment: Abstract no CDD014. Capetown; 2009

doi:10.1186/1471-2334-14-196

Cite this article as: Juma et al:: Monitoring prevention or emergence of HIV drug resistance: results of a population-based foundational survey of early warning indicators in mainland Tanzania. BMC Infectious Diseases 2014 14:196.

\section{Submit your next manuscript to BioMed Central and take full advantage of:}

- Convenient online submission

- Thorough peer review

- No space constraints or color figure charges

- Immediate publication on acceptance

- Inclusion in PubMed, CAS, Scopus and Google Scholar

- Research which is freely available for redistribution

Submit your manuscript at www.biomedcentral.com/submit
C Biomed Central 